\title{
Filling gaps in evapotranspiration measurements for water budget studies: Evaluation of a Kalman filtering approach
}

\author{
Nasim Alavi ${ }^{\text {a }}$, Jon S. Warland ${ }^{\mathrm{a}, *}$, Aaron A. Berg ${ }^{\mathrm{b}}$ \\ ${ }^{a}$ Department of Land Resource Science, University of Guelph, Guelph, Canada N1G2W1 \\ ${ }^{\mathrm{b}}$ Department of Geography, University of Guelph, Guelph, Canada N1G2W1
}

Received 5 May 2006; accepted 29 September 2006

\begin{abstract}
Missing data in long-term eddy covariance measurements of latent heat flux produce errors in the estimation of evapotranspiration and the water budget. Because no standard method of gap filling has been widely accepted, identification of optimal filling methods for gaps is crucial for determining total evapotranspiration. In this study we evaluate the application of a Kalman filter for filling gaps in latent heat flux data collected from an agricultural research station. The filtering approach was compared with several gap-filling methods including mean diurnal variation, multiple regressions, 2-week average Priestley-Taylor coefficient, and multiple imputation. The results demonstrated that a Kalman filtering approach developed using the relationship between latent heat flux, available energy, and vapour pressure deficit provides a closer approximation of the original data and introduces smaller errors than the other methods evaluated. Evaluation of the Kalman filter approach demonstrates the efficiency of this technique in replacing data in both small and large gaps of up to several days.
\end{abstract}

(C) 2006 Elsevier B.V. All rights reserved.

Keywords: Eddy covariance; Missing data; Multiple imputation; Recursive estimation; Data filling

\section{Introduction}

With the proliferation of the eddy covariance system (EC) in the 1980s, direct measurement of evapotranspiration (ET) has become very common (e.g. Aubinet et al., 2000; Baldocchi and Meyers, 1998). Advantages of this technique are high temporal resolution (e.g. half hourly) and integration of the flux over a relatively large area (footprint length of 100-2000 m). The technique is limited by missing or rejected measurements due to system failures (system/sensor breakdown), maintenance and calibration, and improper weather conditions. Today,

\footnotetext{
* Corresponding author. Tel.: +1 519824 4120; fax: +1 5198245730 .

E-mail address: jwarland@uoguelph.ca (J.S. Warland).
}

FluxNet, a world wide network equipped with eddy covariance flux towers, is operating continuously to collect water vapour and $\mathrm{CO}_{2}$ fluxes from more than 140 sites around the world (Baldocchi et al., 2001). However, approximately $17-50 \%$ of the observations in water vapour fluxes are reported as missing or rejected at FluxNet sites (Falge et al., 2001a).

ET measurements are used in estimation of the water budget at daily, monthly and annual time scales. Consequently, data gaps in observed ET must be accurately filled. Accurate assessment of the water budget is required in many studies including contaminant leaching, water available for plant growth and irrigation scheduling. For example, in studies of nitrate leaching from fertilized agricultural fields to ground water, estimation of drainage often depends on knowledge of ET for water budget estimation (e.g. McCoy 
et al., 2006). In many studies, groundwater or soil moisture contributions are estimated as a residual of the water budget equation. Inaccurate estimation of ET perpetuates errors into other aspects of the water budget and its applications. Thus, accurate gap-filling procedures need to be established to provide complete data sets for ET with a minimization of errors.

Numerous methods have been proposed to fill gaps in eddy covariance data but no standard method has been widely accepted. The commonly used methods for filling gaps in water vapour (or latent heat flux) measurements include: the mean diurnal variation method (Falge et al., 2001a,b), regression methods (Greco and Baldocchi, 1996; Berbigier et al., 2001), evaluation of a 2-week average Priestley-Taylor coefficient (Wilson and Baldocchi, 2000; Wilson et al., 2001), look-up tables (Falge et al., 2001b) and multiple imputation (Hui et al., 2004).

Results from different gap-filling methods vary widely. Falge et al. (2001b) filled gaps in annual ET using mean diurnal variation and look-up tables for 28 data sets from 18 FluxNet sites and found that the differences in annual ET among methods ranged from -48 to $+86 \mathrm{~mm}$ per year. Although several gap-filling techniques have been evaluated in replacing missing half hour data (Falge et al., 2001a, b), they have not been evaluated for longer gaps of order of days.

Jarvis et al. (2004) have recently demonstrated the application of a recursive parameter estimation algorithm based on a Kalman filter to fill gaps in $\mathrm{CO}_{2}$ flux data. An approach similar to this technique may be suitable for water vapour flux. However, the efficiency of this technique has not been examined. The Kalman filter is a data assimilation technique that has been applied in various studies. Williams et al. (2005) used an ensemble Kalman filter to evaluate the carbon budget over a ponderosa pine forest. Other studies have examined the ability of Kalman filters to retrieve the soil moisture profile by assimilation of near-surface soil moisture measurements (e.g. Entekhabi et al., 1994; Reichle et al., 2002). In a study of the surface energy balance, Boni et al. (2001) applied a Kalman filtering approach to satellite measurements of surface temperature to estimate the components of the energy balance.

In this study we compared several gap-filling techniques including mean diurnal variation, 2-week average Priestley-Taylor coefficient, regression method, multiple imputation, and recursive parameter estimation algorithms based on the Kalman filter for filling gaps in latent heat flux data. Second, we examined the application of recursive parameter estimation algorithms for filling gaps in latent heat flux data in replacing missing values over short and large gaps in data. We also evaluated the efficiency of this technique in improving the annual and monthly estimation of ET.

\section{Materials and methods}

\subsection{Site description and data collection}

The experimental site was located at the University of Guelph's Elora Research Station $\left(43^{\circ} 39^{\prime}, 80^{\circ} 25^{\prime}\right)$, $25 \mathrm{~km}$ northwest of Guelph, Ontario, Canada. Data used in this study were collected in 2002 over a 18 ha winter wheat field. Measurement of water vapour flux was conducted with two eddy covariance systems. Each system consisted of a Campbell Scientific CSAT3 threedimensional sonic anemometer and a LICOR-7500 open path $\mathrm{CO}_{2} / \mathrm{H}_{2} \mathrm{O}$ analyzer. Net radiation $(\mathrm{Rn})$ and soil heat flux $(G)$ were measured using net radiometers (CNR1 Kipp and Zonen, Delft, the Netherlands) and nine soil heat flux plates (five Model HFT-1, Radiation and Energy Balance Systems Inc., Seattle WA. and four Model 610, Thornthwaite Associates, Elmer, NJ). Air temperature $\left(T_{\mathrm{a}}\right)$ was estimated from measurements by the sonic anemometer and corrected for vapour density.

\subsection{Preparation of data}

\subsubsection{Eddy covariance data}

Quality control was applied to the EC data to exclude potentially non-representative flux measurements. Screening criteria for mean velocity $(\bar{u})$, friction velocity $\left(u^{*}\right)$, and wind direction were applied. During times of weak turbulence or low wind speeds, often experienced at night, mixing is weak and the flux is underestimated. Therefore, we rejected measurements with mean wind $\bar{u}<1 \mathrm{~m} / \mathrm{s}$ and when the friction velocity $u^{*}<0.1 \mathrm{~m} / \mathrm{s}$. To avoid tower shadowing (Lee and $\mathrm{Hu}, 2002$ ), periods where the angle between the mean horizontal wind and sonic axis was more than $150^{\circ}$ were rejected.

The two EC systems were mounted on the same tower during the study period, therefore, the data series of two systems were merged to one time series by averaging two data series when they both had data or by using whichever data was available in the event that one system was not operating.

In 2002 the amount of missing data in latent heat flux $(\lambda E)$ was $17 \%$ (due to maintenance and system failures). The quality tests discarded $27 \%$ of the measured $\lambda E$ data, leading to total gap percentage of $44 \%$ in 2002 with $36 \%$ for day and $54 \%$ for night observations. Fifty-five percent of the total gaps were less than $3 \mathrm{~h}$. 
There were two long gaps of 7 and 14 days in summer 2002 due to field operations.

\subsubsection{Meteorological variables}

The climatic variables, including $\mathrm{Rn}, G, D, T_{\mathrm{a}}$, were missing 4, 5.5, 17 and $17 \%$ of observations respectively, during 2002. Gaps in the $T_{\mathrm{a}}, \mathrm{Rn}$, and vapor pressure (e) time series were filled with the temperature, relative humidity and net radiation measurements also available at a nearby weather station (approximately $200 \mathrm{~m}$ away). Missing values in $G$ were replaced by using a 20 day running linear regression between $G$ and $\mathrm{Rn}$.

\subsection{Gap-filling methods}

The gap-filling methods examined here include: mean diurnal variation (MDV), multiple regressions (Regr.), 2-week average Priestley and Taylor coefficient (PT), multiple imputation (MI), and two recursive parameter estimation algorithms using a Kalman filter.

In this study we evaluated the recursive parameter estimation algorithms as new approaches to gap filling of ET measurements by comparing it with the other methods. The other filling methods where selected because they are commonly used and they each have some advantage. MDV does not require climatic data, therefore it can be used if meteorological variables are not available. Regr. and PT methods consider the impact of climatic variables on ET and capture the response of ET to climatic forcing. MI also preserves the relationships between $\lambda E$ and climatic variables. Furthermore, this method can impute missing climatic variables and missing $\lambda E$ at the same time and provides a confidence level for each imputed value.

\subsubsection{Mean diurnal variation}

In this method, a missing observation is replaced by the mean for that time of day based on observations from the previous and subsequent days (Falge et al., 2001a,b). Derivation of the mean for the missing data depends on the length of the time interval of averaging (window size). A window size of 4-15 days is usually used as the averaging interval. Small window sizes (less than 4 days) were not sufficient to determine a mean from the measurement and not recommended by previous studies (Falge et al., 2001a). Larger window sizes were not considered, because nonlinear dependence of $\lambda E$ on environmental variables introduces errors through averaging. In this study, an averaging interval of \pm 7 days for the missing daytime data day, and \pm 14 days for nighttime data, was found to create the lowest errors, and was therefore used in this study.

\subsubsection{Multiple regression}

In this method a multiple regression relationship was established between latent heat flux and its main controlling factors including available energy $(\mathrm{Rn}-G)$ and vapour pressure deficit $(D)$, for some period around the missing data. The resulting equations were then used to fill the missing latent heat flux values. In this study, a regression relationship for each missing value was calculated using the data from the adjacent \pm 10 days (where \pm 10 days resulted in the highest determination). If the coefficient of determination $\left(R^{2}\right)$ was greater than 0.5 , the resulting equations were used to fill the gap, otherwise the gap remained unfilled. For long gaps (gaps larger than 5 days), data from a window of \pm 20 days were used.

\subsubsection{Two-week average Priestley and Taylor coefficient}

Missing measurements of half hourly latent heat flux were estimated using the product of equilibrium evaporation for the half hour and the 2-week average Priestley and Taylor coefficient (Wilson and Baldocchi, 2000; Wilson et al., 2001). Equilibrium evaporation was obtained using $\lambda E_{\text {eq }}=(\Delta /(\Delta+\gamma))(\mathrm{Rn}-G)$, where $\Delta$ is the slope of saturated vapour pressure with temperature (K), $\gamma$ the psychrometric constant and $\lambda$ is the latent heat of vapourization. For each missing value of $\lambda E$, the total measured $\lambda E$ and estimated $\lambda E_{\mathrm{eq}}$ were obtained during a 2-week period before and after the missing value of $\lambda E$ and the Priestley and Taylor coefficient $\left(\alpha=\lambda E / \lambda E_{\text {eq }}\right.$, Priestley and Taylor, 1972) was calculated. At the time of the missing $\lambda E$ measurement the product of $\alpha$ and $\lambda E_{\mathrm{eq}}$ was used to estimate missing $\lambda E$ following Wilson and Baldocchi (2000).

\subsubsection{Multiple imputation}

Multiple imputation (MI) is a statistical technique for analyzing incomplete data sets (Hui et al., 2004). In this technique, the missing entries of the incomplete data sets are imputed $m$ times. The variation among the $m$ imputations reflects the uncertainty with which the missing values can be predicted from the observed ones. In order to generate imputations for the missing values, a probability model must be imposed on the complete data set (observed and missing values). Once the model is selected, mean vector and covariance matrices of the incomplete data set can be generated using the expectation and maximization algorithm (EM). The EM algorithm is a common technique for fitting models to incomplete data and estimating mean and covariance matrices (Rubin, 1987; Schafer and Olsen, 1998). Then 
a data augmentation algorithm uses the initial values obtained from the EM algorithm and generates the imputed values. Further details of this method are given in Hui et al. (2004) and Schafer (1997).

For this study, we assumed multivariate normal distribution for observed $\lambda E$ and the climatic variables. A number of previous studies (e.g. Schafer, 1997) have shown that MI is robust to violations from the normality of values used in the analysis if the amount of missing values is not large. We examined the assumption of multivariate normal distribution by transforming data using the Box-Cox transformation method provided in SAS software version 9.1 (SAS Institute Inc., 2004) following Hui et al. (2004). Comparison of the results of transformed data with non-transformed data indicated that the annual estimations changed only slightly (about $0.03 \%$ ). We also assumed that data were missing at random (MAR). Under this assumption, the probability that data are missing may depend on observed data but not on ones that are missing. This assumption allows us to first estimate the relationships among variables from the observed data, and then use these relationships to obtain unbiased predictions of the missing values from the observed data. This assumption is plausible for the $\lambda E$ data since most of the missing data were due to improper wind conditions (e.g. low $u^{*}$ ) or malfunction of the instruments and only weakly related to $\lambda E$ itself (e.g. when condensation occurs on the gas analyzer). In our evaluation procedure (Section 2.4) this assumption is strictly valid because data are removed randomly.

A matrix of observations of $\lambda E$ and available energy $(\mathrm{Rn}-G), T_{\mathrm{a}}$, and $D$ was used to conduct MI analysis. MI analysis was conducted using SAS software version 9.1 (SAS Institute Inc., 2004). The analysis used an EM algorithm (maximum number of iteration used in EM was set to 500) for initial value estimations and five imputations were created using a data augmentation algorithm, Markov Chain Monte Carlo (MCMC). Rubin (1987) and Schafer and Olsen (1998) showed that unless the rate of missing information is very high only a few imputations (3-5) are enough to estimate missing data and there is little advantage to producing and analyzing more than a few imputed datasets. The average of the five imputed values was used to fill each missing observation.

\subsubsection{Recursive parameter estimation algorithms}

This method is based on the Kalman filter and smoothing techniques developed by Young and coworkers (Young, 1999; Young and Pedregal, 1999; Young et al., 2004). In this method, the system is described by a proper model with unknown parameters (observation model). Temporal variations of parameters in this model are assumed to be described by a generalized random-walk model (state model). Having introduced these two models, a forward pass filtering (Kalman filter) is applied to the data to predict time variable model parameters. The estimates obtained from the Kalman filter are updated using a backward recursive smoothing algorithm working through the data in reverse temporal order. Based on the type of observation model, different methodologies have been introduced for applying recursive parameter estimation. In this study dynamic linear regression (DLR) and state dependent parameters (SDP) were applied to the $\lambda E$ data using the Captain Toolbox for MATLAB (Young et al., 2004).

In the DLR algorithm, parameters are considered to vary with time. In this study, the regression model was expressed as the relationship between $\lambda E$, net radiation $(\mathrm{Rn})$, and vapour pressure deficit $(D)$ :

$$
\lambda E(t)=\alpha(t)(\operatorname{Rn}(t)-G(t))+\beta(t) D(t)+\zeta(t)
$$

Here $\alpha(t)$ and $\beta(t)$ are the model parameters and $\xi$ is the regression model error series that is zero mean (white noise). The DLR parameters can be seen as coefficients in the Penman-Montheith equation:

$\lambda E=\frac{\Delta}{\Delta+\gamma^{*}}(\operatorname{Rn}-G)+\frac{\rho_{\mathrm{a}} C_{p}}{r_{\mathrm{a}}\left(\Delta+\gamma^{*}\right)} D$

where $\gamma^{*}=\gamma\left(1+\left(r_{\mathrm{c}} / r_{\mathrm{a}}\right)\right), \rho_{\mathrm{a}}$ is the air density, $C_{p}$ the specific heat at constant pressure, $r_{\mathrm{a}}$ the aerodynamic resistance, $r_{\mathrm{c}}$ the canopy resistance and $\gamma$ is the psychrometric constant.

The stochastic evolution of each parameter in (1) is assumed to be described by the following random walk process (Young, 1999):

$\alpha(t)=\alpha(t-1)+\eta_{\alpha}(t), \quad \beta(t)=\beta(t-1)+\eta_{\beta}(t)$

and $\eta_{\alpha}, \eta_{\beta}$ are zero mean, white noise error series.

In the SDP algorithm, parameters are dependent on air temperature $\left(T_{\mathrm{a}}\right)$ as well as time:

$\lambda E(t)=\alpha\left(T_{\mathrm{a}}, t\right)(\operatorname{Rn}(t)-G(t))+\beta\left(T_{\mathrm{a}}, t\right) D(t)+\zeta(t)$

where

$$
\begin{gathered}
\alpha\left(T_{\mathrm{a}}, t\right)=\alpha\left(T_{\mathrm{a}}, t-1\right)+\eta_{\alpha}(t), \\
\beta\left(T_{\mathrm{a}}, t\right)=\beta\left(T_{\mathrm{a}}, t-1\right)+\eta_{\beta}(t)
\end{gathered}
$$

and $\eta_{\alpha}, \eta_{\beta}$ are zero mean, white noise error series. We assumed that the evolution of the model parameters is 
nonstationary stochastic as described by a simple random walk process. This ensures that the recursive parameter estimates at any sample time $t$ depends only on data in the vicinity of this sample. This weighting effect has a Gaussian shape which applies the maximum weight at sample time $t$ with declining weight each side. The bandwidth of the Gaussian window is defined by the noise variance ratio (NVR) $\left(\mathrm{NVR}=\sigma^{2}(\zeta(t))\right.$ / $\sigma^{2}(\eta(t))$. The required NVRs are optimized via maximum likelihood error decomposition introduced by Young (1999).

When using the SDP method the state dependent parameters may vary with $T_{\mathrm{a}}$ at a rate commensurate with the temporal variations in the input series, thus a simple random walk cannot be assumed to describe the parametric variation over time. Therefore, before estimation of parameter variation, the time series of $\lambda E, \mathrm{Rn}, G$, and $D$ were sorted with respect to the ascending order of $T_{\mathrm{a}}$. With sorting, the rapid natural variations in the input series are effectively eliminated from the data and a simple random walk process utilized to describe their evolution (Jarvis et al., 2004).

\subsection{Evaluation of gap-filling methods}

We created random and systematic gaps in the data sets and applied each of the methods to fill these gaps. The analysis used four bimonthly data sets (FebruaryMarch, April-May, June-July and September-November for the 2002 data) with low percentages (25-35\%) of missing and rejected data. Daytime and nighttime data were treated separately. Half hourly data were deleted randomly until 20\% (about 100-180 data points) of the original daytime data was removed from the bimonthly dataset. Then each of the gap-filling methods was applied to fill these artificial gaps. This procedure was repeated for the nighttime data. To assess the performance of each we examined the potential error associated with each method. Root mean square error (RMSE), coefficient of determination $\left(R^{2}\right)$, relative root mean square error (R_RMSE), and relative bias (R_bias) were calculated. The absolute error for each method was calculated as the measured minus the computed value for each artificially missed data and was used to calculate the total RMSE for the each bimonthly data set. It was divided by the mean of $\lambda E$ for the data set to calculate R_RMSE. $R^{2}$ was computed between the observed and filled data for each bimonthly data set and R_bias was obtained by dividing the bias by the mean of $\lambda E$ for each data set. The entire procedure was performed three times and the average values reported here.

\section{Results and discussion}

\subsection{Results of filling artificial gaps in data}

Table 1 compares the performance of the gap-filling methods. For the daytime data, root mean square errors in each bi-monthly period range from 10.5 to $70.3 \mathrm{~W} /$ $\mathrm{m}^{2}$. The DLR technique resulted in the smallest error (average RMSE $=17.2 \mathrm{~W} / \mathrm{m}^{2}$ ) and largest agreement coefficient (average $R^{2}=0.93$ ), while the largest errors (average RMSE $=54.1 \mathrm{~W} / \mathrm{m}^{2}$ ) were found with the PT method. The smallest agreement coefficients (average $R^{2}=0.5$ ) were obtained with MDV. Unlike the other methods MDV, does not consider the impact of meteorological variables on $\lambda E$ so it can be used when meteorological data are not available.

The root mean square errors for nighttime gaps ranged from 5.1 to $38.4 \mathrm{~W} / \mathrm{m}^{2}$ and the agreement coefficients were all less than 0.5. Comparing the different methods, the errors were smallest (average $\mathrm{RMSE}=11.3 \mathrm{~W} / \mathrm{m}^{2}$ ) with DLR whereas PT resulted in the largest error $\left(33.7 \mathrm{~W} / \mathrm{m}^{2}\right)$. RMSEs are larger during summer and daytime than winter and nighttime, but the fluxes are also larger. Therefore we considered the relative RMSE to make the comparison between different seasons and time. Normalizing the RMSE with the mean of $\lambda E$ for each dataset (relative root mean square error) shows that all gap-filling methods resulted in smaller relative errors (0.1-0.5) during summer (June-July) and spring (April-May) than fall (OctoberNovember) and winter (February-March) (0.3-1.5). Also better agreement between computed and original values was obtained during summer and spring daytime (greater than $70 \%$ except for MDV).

R_bias was mostly less than 5\% for daytime datasets except for the PT method. This shows that the error introduced by the different methods is essentially random.

The gaps in daytime data during the summer can be filled with smaller relative errors than nighttime and wintertime gaps. The large relative errors associated with filling missing nighttime data is primarily related to the large number of gaps in nighttime data and unreliable measurements during nighttime. However, due to the low nighttime value of $\lambda E$, the error introduced by application of different filling method may not influence the total annual or monthly estimation of $\lambda E$ significantly.

For the evaluation process, gaps in the data were created randomly. This may not be a true representation of reality because real gaps in data may not be randomly distributed. Most large gaps in the data were due to unsuitable weather conditions or field operations. These 
Table 1

Root mean square error (RMSE), agreement coefficient $\left(R^{2}\right)$, relative root mean square error (R_RMSE), and relative bias (R_bias) of gap filled $\lambda E$ $\left(\mathrm{W} / \mathrm{m}^{2}\right)$

\begin{tabular}{|c|c|c|c|c|c|c|}
\hline & Regr. & MDV & $\mathrm{PT}$ & DLR & SDP & MI \\
\hline \multicolumn{7}{|l|}{ Daytime data } \\
\hline \multicolumn{7}{|l|}{ RMSE } \\
\hline April-May 2002 & 30.22 & 55.08 & 42.67 & 19.46 & 28.83 & 40.41 \\
\hline June-July 2002 & 33.68 & 70.26 & 53.59 & 22.80 & 44.67 & 52.40 \\
\hline October-November 2002 & 20.20 & 29.52 & 61.15 & 16.19 & 22.98 & 29.14 \\
\hline February-March 2002 & 20.64 & 27.96 & 59.15 & 10.47 & 21.09 & 18.13 \\
\hline Average & 26.18 & 45.70 & 54.14 & 17.23 & 29.39 & 35.02 \\
\hline \multicolumn{7}{|l|}{$R^{2}$} \\
\hline April-May 2002 & 0.83 & 0.44 & 0.79 & 0.93 & 0.85 & 0.72 \\
\hline June-July 2002 & 0.93 & 0.67 & 0.86 & 0.97 & 0.87 & 0.81 \\
\hline October-November 2002 & 0.80 & 0.58 & 0.55 & 0.88 & 0.76 & 0.62 \\
\hline February-March 2002 & 0.71 & 0.46 & 0.51 & 0.92 & 0.68 & 0.74 \\
\hline Average & 0.82 & 0.54 & 0.68 & 0.93 & 0.79 & 0.72 \\
\hline \multicolumn{7}{|l|}{ R_RMSE } \\
\hline April-May 2002 & 0.29 & 0.54 & 0.42 & 0.19 & 0.28 & 0.39 \\
\hline June-July 2002 & 0.19 & 0.39 & 0.29 & 0.13 & 0.25 & 0.29 \\
\hline October-November 2002 & 0.40 & 0.58 & 1.21 & 0.32 & 0.45 & 0.55 \\
\hline February-March 2002 & 0.53 & 0.72 & 1.53 & 0.27 & 0.55 & 0.50 \\
\hline Average & 0.35 & 0.56 & 0.86 & 0.23 & 0.38 & 0.43 \\
\hline \multicolumn{7}{|l|}{ R_bias } \\
\hline April-May 2002 & 0.02 & 0.04 & -0.09 & -0.02 & -0.05 & 0.04 \\
\hline June-July 2002 & -0.03 & 0.00 & -0.05 & 0.00 & 0.00 & -0.02 \\
\hline October-November 2002 & -0.02 & -0.05 & -0.54 & -0.04 & -0.06 & -0.02 \\
\hline February-March 2002 & -0.04 & 0.03 & -0.80 & 0.01 & -0.01 & 0.00 \\
\hline Average & -0.04 & 0.02 & -0.37 & -0.02 & -0.03 & 0.00 \\
\hline \multicolumn{7}{|l|}{ Nighttime data } \\
\hline \multicolumn{7}{|l|}{ RMSE } \\
\hline April-May 2002 & 13.62 & 15.83 & 25.76 & 11.41 & 13.25 & 22.51 \\
\hline June-July 2002 & 17.88 & 17.83 & 38.43 & 15.61 & 20.35 & 29.29 \\
\hline October-November 2002 & 16.06 & 19.28 & 37.49 & 13.11 & 16.60 & 19.23 \\
\hline February-March 2002 & 9.34 & 10.52 & 32.96 & 5.15 & 9.35 & 12.83 \\
\hline Average & 14.22 & 15.86 & 33.66 & 11.32 & 14.89 & 20.96 \\
\hline \multicolumn{7}{|l|}{$R^{2}$} \\
\hline April-May 2002 & 0.23 & 0.00 & 0.19 & 0.41 & 0.27 & 0.03 \\
\hline June-July 2002 & 0.20 & 0.00 & 0.02 & 0.35 & 0.18 & 0.00 \\
\hline October-November 2002 & 0.17 & 0.00 & 0.03 & 0.46 & 0.19 & 0.07 \\
\hline February-March 2002 & 0.27 & 0.04 & 0.02 & 0.75 & 0.24 & 0.02 \\
\hline Average & 0.22 & 0.01 & 0.07 & 0.49 & 0.22 & 0.03 \\
\hline \multicolumn{7}{|l|}{ R_RMSE } \\
\hline April-May 2002 & 0.88 & 1.03 & 1.67 & 0.74 & 0.86 & 1.52 \\
\hline June-July 2002 & 1.07 & 1.06 & 2.29 & 0.93 & 1.21 & 1.76 \\
\hline October-November 2002 & 1.15 & 1.38 & 2.69 & 0.93 & 1.18 & 1.43 \\
\hline February-March 2002 & 0.99 & 1.11 & 3.48 & 0.55 & 0.99 & 1.47 \\
\hline Average & 1.02 & 1.14 & 2.53 & 0.79 & 1.06 & 1.54 \\
\hline \multicolumn{7}{|l|}{ R_bias } \\
\hline April-May 2002 & -0.16 & 0.09 & 1.28 & 0.04 & -0.21 & -0.10 \\
\hline June-July 2002 & 0.53 & 0.14 & 1.84 & -0.40 & 0.74 & 0.53 \\
\hline October-November 2002 & -0.09 & 0.05 & 1.94 & -0.16 & -0.36 & 0.05 \\
\hline February-March 2002 & -0.15 & 0.12 & 2.69 & 0.01 & 0.02 & -0.05 \\
\hline Average & 0.03 & 0.10 & 1.94 & -0.13 & -0.31 & 0.11 \\
\hline
\end{tabular}


gaps may introduce biases by their non-random distribution. Therefore the resultant errors with artificial gaps may not be equivalent to the errors from application of filling methods to the real gaps. To evaluate the application of the gap-filling methods over longer gaps as would be expected from bad weather conditions or instrument failure, in the following section we assess the top three methods (Regr., DLR and SDP) for long gaps on order of few hours to days.

Lack of energy balance closure is a common problem in measuring turbulent fluxes with EC technique. It has become generally accepted that the turbulent fluxes (sensible heat and latent heat fluxes) are underestimated by approximately $10-30 \%$ relative to estimate of available energy (Wilson et al., 2002; Aubinet et al., 2000). Closure has not been considered in this analysis, however since the gap-filling methods are essentially interpolative, correcting existing data for closure would produce an equal change in the filled data.

\subsection{The Kalman filter approach to filling long gaps}

This section examines the efficiency of SDP, DLR and Regr. methods in replacing data in large gaps by creating $3,6,12,18 \mathrm{~h}$, and $1,3,5$ and 7 day gaps in the dataset. As an example, the results for a 3-day gap in May 2002 are shown in Fig. 1. For this period the RMSE for DLR was $8.2 \mathrm{~W} / \mathrm{m}^{2}$ and for SDP $13.4 \mathrm{~W} / \mathrm{m}^{2}$, while it was $20.6 \mathrm{~W} / \mathrm{m}^{2}$ for Regr. Next, a 1-day moving gap was created throughout the growing season (May-September 2002). Fig. 2 shows the resulting RMSE for each day of growing season 2002. In general, the values of RMSE are smaller for DLR than Regr. and SDP. The average daily RMSE was $22.4 \mathrm{~W} / \mathrm{m}^{2}$ with DLR, $33.2 \mathrm{~W} / \mathrm{m}^{2}$ with SDP, and $30.2 \mathrm{~W} / \mathrm{m}^{2}$ with Regr. This procedure was repeated using moving gap sizes of 3,6 , 12, $18 \mathrm{~h}$ and 2, 3, 5, 7 days over May-September 2002. Fig. 3 shows the average RMSE for different gap sizes. As the size of gap increases, mean RMSE of DLR, SDP and Regr. increases. DLR outperformed the other methods for all gap sizes and has the smallest mean RMSE while SDP has the greatest mean RMSE for all gap sizes. The difference in mean RMSE between Regr. and DLR is $6.8 \mathrm{~W} / \mathrm{m}^{2}$ for $3 \mathrm{~h}$ gaps and decreases to $3.4 \mathrm{~W} / \mathrm{m}^{2}$ for a gap size of 7 days.

In the SDP method, the $\lambda E$ time series are sorted out of temporal order. Jarvis et al. (2004) claimed that in this case the systematic gaps in the time series become
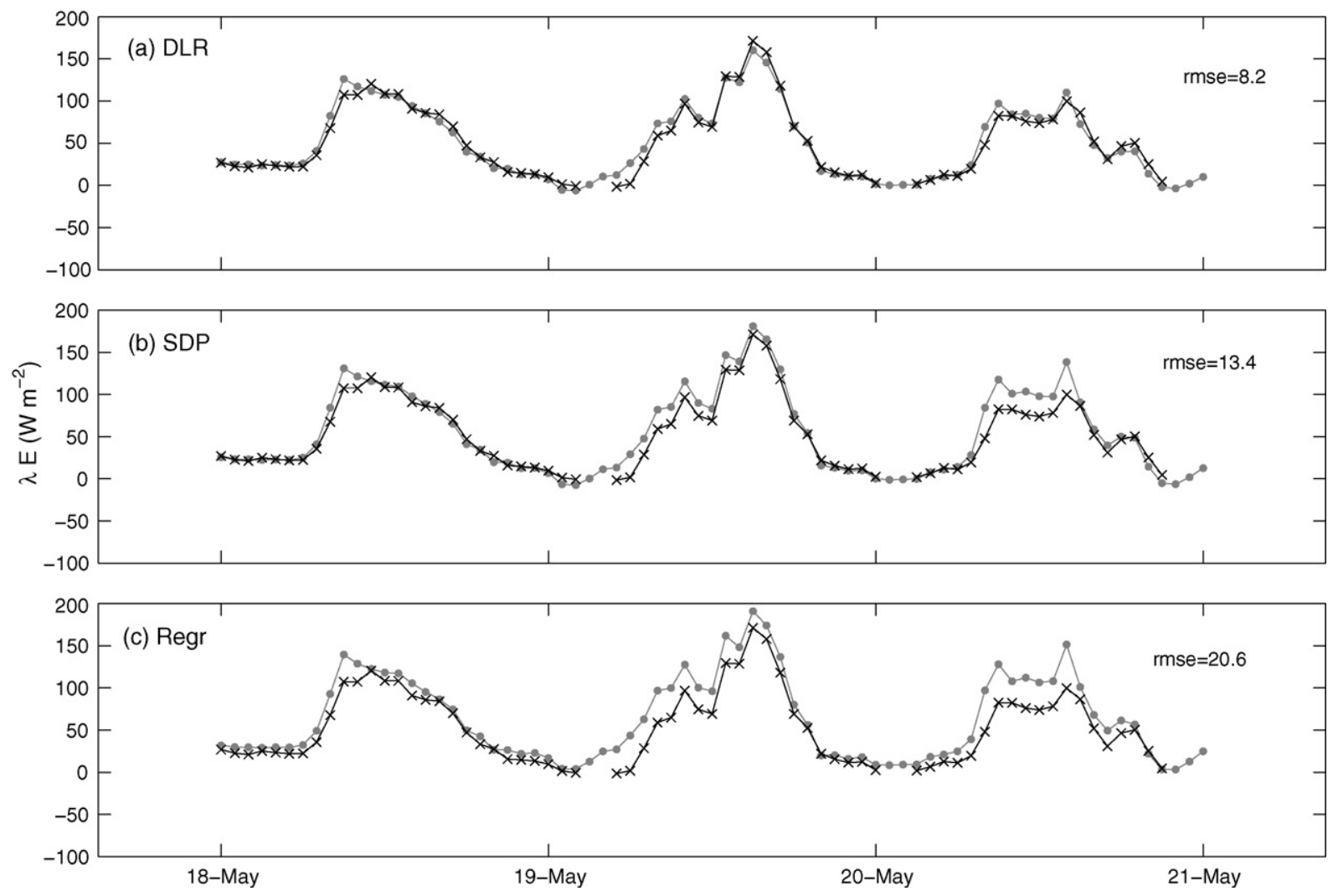

Fig. 1. Comparison of gap filled $\lambda E$ (๑) by (a) DLR, (b) SDP, and (c) Regr. with measurements (×) for 18-21 May 2002. 

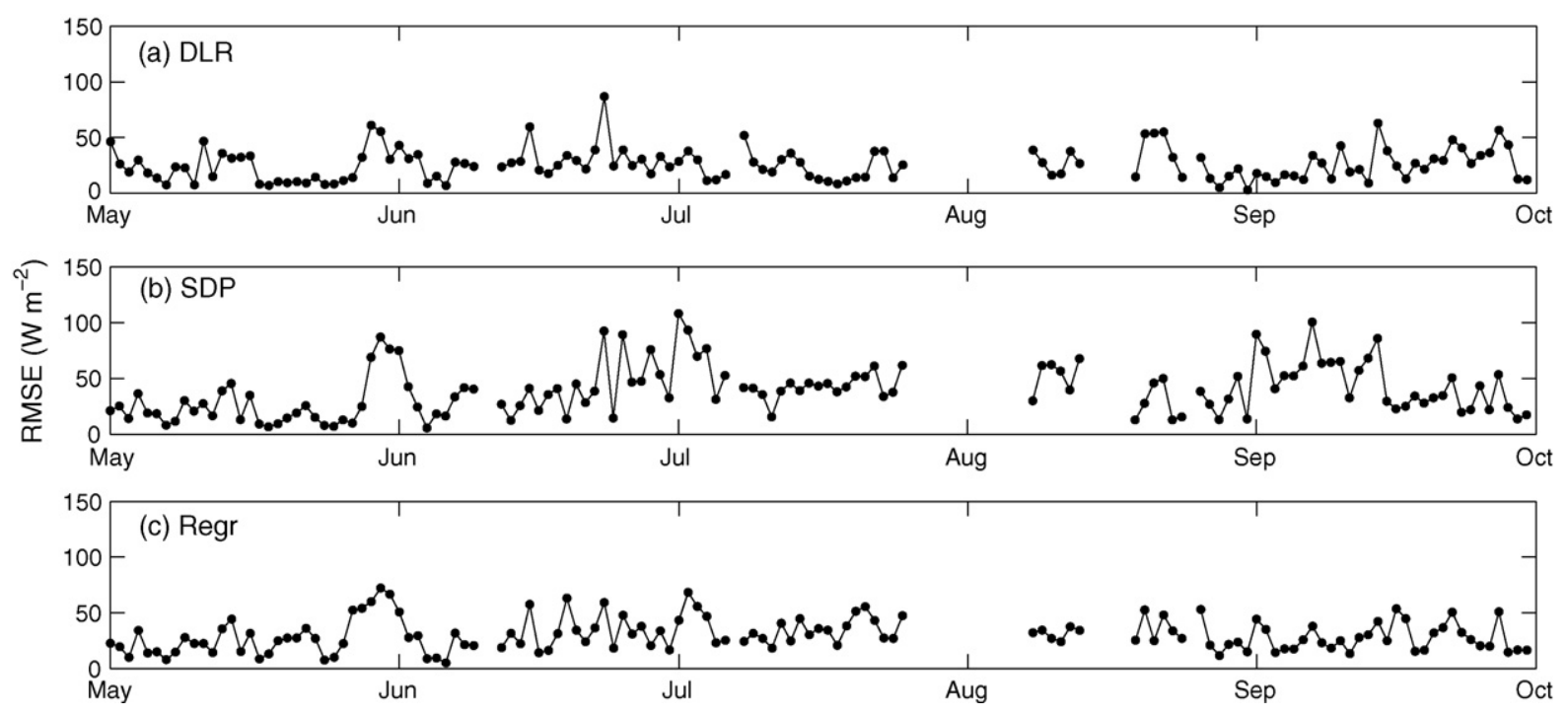

Fig. 2. RMSE of (a) Regr., (b) DLR, and (c) SDP for 1 day moving gap in growing season 2002.

much smaller nonsystematic gaps in the sorted temperature space and these smaller gaps can be filled with smaller errors. Therefore, we should expect better estimation of data in longer gaps using SDP. However, in this study the SDP approach gave larger errors for all gap sizes compared to DLR. In the SDP algorithm the time series of Rn, $G$ and $D$ were also sorted with respect to the ascending order of $T_{\mathrm{a}}$. Although there is some correlation of these variables with air temperature, other factors are also significant. The assumption that $T_{\mathrm{a}}$ is the dominant control may lead to greater errors in SDP analysis.

Including more variables in the algorithm would increase the complexity of the model and result in large errors comparing to simpler DLR algorithm.

Application of the DLR method provides a very good estimation of missing values in $\lambda E$ since it is able to reproduce most variation in $\lambda E$ due to different factors (e.g. net radiation, vapour pressure). It provides smaller RMSEs (3.4-6.8 W/m², with the lower values for gap

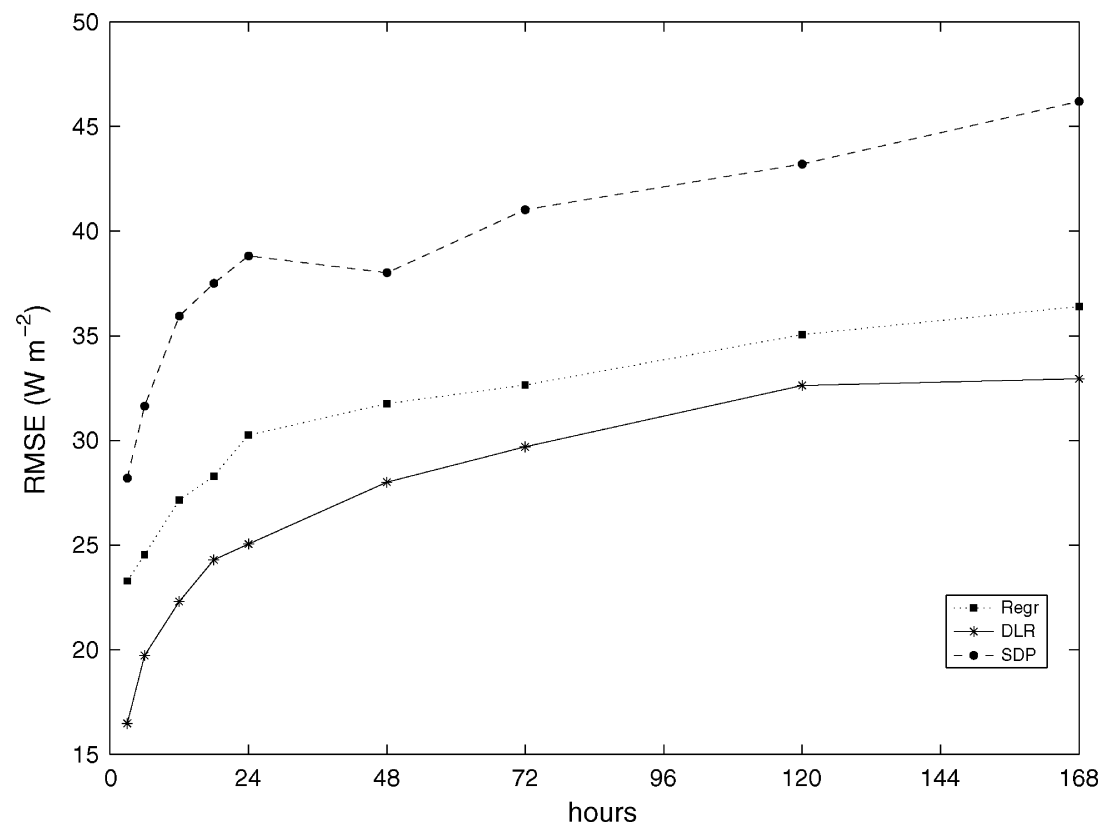

Fig. 3. Mean RMSE of Regr., SDP, and DLR for filling in 3, 6, 12, $18 \mathrm{~h}$ and 1, 2, 3, 5, 7 days moving gaps in growing season 2002. 
sizes of $3 \mathrm{~h}$ to 7 days) than Regr. for estimating $\lambda E$. Similar to the analysis over random gaps, the DLR method was the most accurate for filling the larger artificial gaps.

\subsection{Estimation of annual and monthly sum of ET}

Annual sums of ET were computed by filling the real gaps with the Regr. and DLR methods. Regr. method was applied to data with a window of \pm 10 . Since some gaps were not filled because of low agreement coefficients (mostly in winter time) we repeated the application of Regr. using windows of \pm 20 and \pm 30 days to fill data left unfilled by the 10-day window.

The annual estimation of ET was $606 \mathrm{~mm}$ by Regr., and it was 585 by DLR which differ by $21 \mathrm{~mm}(3 \%)$. Although the application of Regr. and DLR did not affect the annual sum very much, estimating ET during a shorter period of time might be highly affected by the filling method.

The results for monthly estimation of ET for year 2002 showed that the difference in monthly ET filled by Regr. and by DLR ranged from 1 to $8 \mathrm{~mm}(0.2-15 \%)$ for different months. The absolute difference was small during winter months $(0.2-1.5 \mathrm{~mm})$ while it was larger in the growing season $(4-8 \mathrm{~mm})$. Therefore, the selection of proper gap-filling method is crucial in estimating monthly ET during growing season.

\section{Summary}

Several gap-filling methods were applied to eddy covariance data of latent heat flux from an agricultural site. The methods were evaluated based on their ability to fill artificial data gaps. The recursive parameter estimation approach based on the relation between latent heat flux and available energy and vapour pressure deficit resulted in better estimation of the original data and smaller errors than the MI, PT and MDV, and Regr. methods.

The recursive parameter estimation approach with the DLR algorithm produced the smallest errors for both short and long (hours to days) gaps. The relative errors were smaller for daytime data during the growing season, when ET is high, than for nighttime and winter data. The application of this method can improve the estimation of total ET over a period of time since it results in smaller errors than other methods, assuming no significant bias between missing and present data (MAR is valid).

While the application of different gap-filling techniques does not greatly affect influence the total annual sum, the total ET for shorter periods of time (month or days) can be highly affected by choice of gapfilling technique. Total ET during the growing season, when ET is high, is more sensitive to choice of gapfilling method and so proper selection of a method is crucial at this time. Since the evaluation process based on filling artificial gaps showed that the resultant error with DLR was smaller than with other methods, application of this technique should provide better estimation of total ET, especially over a short period of time and during the growing season.

Due to the efficiency of the Kalman filtering approach in replacing data in both small and large gaps, and providing the best approximation of the original data, the application of this technique is recommended as a gapfilling approach for estimation of total ET, as is further study of these techniques on the other contexts.

\section{Acknowledgements}

This research project was funded by the grants from the Ontario Ministry of Agriculture and Food and the Natural Sciences and Engineering Research Council of Canada. We are very grateful for the thoughtful and detailed comments of the two anonymous reviewers.

\section{References}

Aubinet, M., Grelle, A., Ibrom, A., Rannik, Ü., Moncrieff, J., Foken, T., Kowalski, A.S., Martin, P.H., Berbigier, P., Bernhofer, Ch., Clement, R., Elbers, J., Granier, A., Grünwald, T., Morgenstern, K., Pilegaard, K., Rebmann, C., Snijders, W., Valentini, R., Vesala, T., 2000. Estimates of the annual net carbon and water exchange of European forests: the EUROFLUX methodology. Adv. Ecol. Res. 30, 113-175.

Baldocchi, D., Meyers, T., 1998. On using eco-physiological, micrometeorological and biogeochemical theory to evaluate carbon dioxide, water vapour and trace gas fluxes over vegetation: a perspective. Agric. For. Meteorol. 90, 1-25.

Baldocchi, D., Falge, E., Gu, L., Olson, R., Hollinger, D., Running, S., Anthoni, P., Bernhofer, C., Davis, K., Evans, R., Fuentes, J., Goldstein, A., Katul, G., Law, B., Lee, X., Malhi, Y., Meyers, T., Munger, W., Oechel, W., Paw, U.K.T., Pilegaard, K., Schmid, H.P., Valentini, R., Verma, S., Vesala, T., Wilson, K., Wofsy, S., 2001. FLUXNET: a new tool to study the temporal and spatial variability of ecosystem-scale carbon dioxide, water vapour and energy flux densities. Bull. Am. Meteorol. Soc. 82, 2415-2434.

Berbigier, P., Bonnefond, J.M., Mellmann, P., 2001. $\mathrm{CO}_{2}$ and water vapour fluxes for 2 years obove Euroflux forest site. Agric. For. Meteorol. 108, 183-197.

Boni, G., Entekhabi, D., Gastelli, F., 2001. Land data assimilation with satellite measurements for the estimation of surface energy balance components and surface control on evaporation. Water Resour. Res. 37 (6), 1713-1722.

Entekhabi, D., Nakamura, H., Njoku, E.G., 1994. Solving the inverse problem for soil moisture and temperature profiles by sequential 
assimilation of multifrequency remotely sensed observations. IEEE Trans. Geosci. Remote Sensing 32 (2), 438-448.

Falge, E., Baldocchi, D.D., Olson, R., Anthoni, P., Aubinet, M., Bernhofer, C., Burba, G., Ceulemans, R., Clement, R., Dolman, H., Granier, A., Gross, P., Grunwald, T., Hollinger, S., Jensen, N.O., Katul, G., Keronen, P., Kowalski, A., Lai, C.T., Law, B.E., Meyers, T., Moncrieff, J., Moors, E., Munger, J.W., Pilegaard, K., Rannik, U., Rebmann, C., Suyker, A., Tenhunen, J., Tu, K., Verma, S., Vesala, T., Wilson, K., Wofsy, S., 2001a. Gap filling strategies for defensible annual sums of net ecosystem exchange. Agric. For. Meteorol. 107, 43-69.

Falge, E., Baldocchi, D.D., Olson, R., Anthoni, P., Aubinet, M., Bernhofer, C., Burba, G., Ceulemans, R., Clement, R., Dolman, H., Granier, A., Gross, P., Grunwald, T., Hollinger, S., Jensen, N.O., Katul, G., Keronen, P., Kowalski, A., Lai, C.T., Law, B.E., Meyers, T., Moncrieff, J., Moors, E., Munger, J.W., Pilegaard, K., Rannik, U., Rebmann, C., Suyker, A., Tenhunen, J., Tu, K., Verma, S., Vesala, T., Wilson, K., Wofsy, S., 2001b. Gap filling strategies for long term energy flux data sets. Agric. For. Meteorol. 107, 71-77.

Greco, S., Baldocchi, D.D., 1996. Seasonal variations of $\mathrm{CO}_{2}$ water vapour exchange rates over a temperate deciduous forest. Global Change Biol. 2, 183-197.

Hui, D., Wan, S., Su, B., Katul, G., Monson, R., Luo, Y., 2004. Gapfilling missing data in eddy covariance measurements using multiple imputation (MI) for annual estimations. Agric. For. Meteorol. 121, 93-111.

Jarvis, A.J., Stauch, V.J., Schulz, K., Young, P.C., 2004. The seasonal temperature dependency of photosynthesis and respiration in two deciduous forests. Global Change Biol. 10, 939-950.

Lee, X.H., Hu, X.Z., 2002. Forest-air fluxes of carbon, water and energy over non-flat terrain. Boundary-Layer Meteorol. 103 (2), 277-301.

McCoy, A.J., Parkin, G.W., Wagner-Riddle, C., Warland, J.S., Lauzon, J., von Bertoldi, P., Fallow, D., Jayasundara, S., 2006. Using automated soil water content and temperature measurement systems to estimate soil water budgets. Can. J. Soil Sci. 86, 47-56.
Priestley, C.H.B., Taylor, R.J., 1972. On the assessment of surface heat flux and evaporation using large-scale parameters. Monthly Weather Rev. 100, 81-92.

Reichle, R., McLaughlin, D.B., Entekhabi, D., 2002. Hydrologic data assimilation with the ensemble Kalman filter. Monthly Weather Rev. 130 (1), 103-114.

Rubin, D.B., 1987. Multiple Imputation for Nonresponse Surveys. John Wiley \& Sons, New York.

Schafer, J.L., Olsen, M.K., 1998. Multiple imputation for multivariate missing-data problems: a data analyst's perspective. Multivariate Behav. Res. 33, 545-571.

Schafer, J.L., 1997. Analysis of Incomplete Multivariate Data. Chapman and Hall, London.

Williams, M., Schwarz, P.A., Law, B.E., Irvine, J., Kurpius, M.R., 2005. An improved analysis of forest carbon dynamics using data assilmilation. Global Change Biol. 11, 89-105.

Wilson, K.B., Baldocchi, D.D., 2000. Seasonal and interannual variability of energy fluxes over a broadleaved temperate deciduous forest in North America. Agric. For. Meteorol. 100, 1-18.

Wilson, K.B., Hanson, P.J., Mulholland, P.J., Baldocchi, D.D., Wullschleger, S.D., 2001. A comparison of methods for determining forest evapotranspiration and its components: sap-flow, soil water budget, eddy covariance and catchment water balance. Agric. For Meteorol. 106, 153-168.

Wilson, K.B., Goldstein, A.H., Falge, E., Aubinet, M., Baldocchi, D., Berbigier, P., Bernhofer, Ch., Ceulemans, R., Dolman, H., Field, C., Grelle, A., Law, B., Meyers, T., Moncrieff, J., Monson, R., Oechel, W., Tenhunen, J., Valentini, R., Verma, S., 2002. Energy balance closure at FLUXNET sites. Agric. For. Meteorol. 113, 223-243.

Young, P.C., 1999. Nonstationary time series analysis and forecasting. Progr. Environ. Sci. 1, 3-48.

Young, P.C., Pedregal, D.J., 1999. Recursive and en-bloc approaches to signal extraction. J. Appl. Stat. 26, 103-128.

Young, P.C., Taylor, C.J., Tych, W., Pedregal, D.J., McKenna, P.G., 2004. The Captain Toolbox. Centre for Research on Environmental Systems and Statistics, Lancaster University (http://www.es.lancs.ac.uk/cres/captain). 